\title{
Color Doppler Ultrasonography: An Affordable Diagnostic Tool for Acute Scrotal Management
}

\author{
Mahmuda Monowara' ${ }^{1 *}$, Afsana Habib Sheuly², Ipsita Biswas ${ }^{3}$, Mahabuba Nasrinn', Abdul Aziz ${ }^{5}$ \\ ${ }^{1}$ Assistant professor, Dept. Of Radiology and Imaging, Bangladesh \\ ${ }^{2}$ Epidemiologist, National Institute of Ophthalmology and Hospital, Bangladesh \\ ${ }^{3}$ Associate Professor, BICH and Dhaka Shishu Hospital, Bangladesh \\ ${ }^{4}$ Medical Officer, Bangladesh \\ ${ }^{5}$ Professor and head, Dept. of Pediatric Urology and Director, Bangladesh
}

Received date: October 2, 2018; Published date: October 31, 2018

*Corresponding author: Mahmuda Monowara, Department of Radiology \&Imaging, BICH and Dhaka Shishu Hospital, Bangladesh,

Email: mahmudamonowara085@gmail.com

\begin{abstract}
Introduction: Acute scrotal management for pain needs early decision for patients' benefits. If we can diagnose properly, unnecessary surgical exploration can be reduced. Aim of this study is to see the efficacy of color Doppler Ultra Sonography (US) as diagnostic tool for scrotal management.

Methods: It was a prospective observational study of 3 years where we examined 153 patients of acute scrotal pain. Follow up confirmation was done after scrotal exploration or by clinical follow up.

Result: Out of 153 patients, majority were diagnosed as epididymis-orchitis 83(54.25\%) and torsion 55(35.95\%). As diagnostic tool, color Doppler US was $100 \%$ specific and $95.4 \%$ sensitive for epididymis -orchitis and for torsion it was found $100 \%$ specific and $94.8 \%$ sensitive.

Conclusion: Color Doppler US can be an affordable tool for diagnosis.

Keywords: Color Doppler; Torsion; Epididymis-orchitis
\end{abstract}

\section{Introduction}

Acute Scrotal condition is an emergency. To diagnosis confidently in a non -invasive procedure is very important. In ischemic disease condition of scrotum like torsion of testis it is beneficial to do surgery but if it not then the burden of treatment cost to patient is unnecessary. Acute scrotum is defined as acute pain with or without scrotal swelling, may be accompanied by local signs or general symptoms. The most common differential diagnoses of the acute scrotum include:

a. Torsion of the spermatic cord and

b. Acute epididymitis or epididymis-orchitis. Less common diagnoses include: Strangulated hernia, segmental testicular infarction, testicular tumor, and idiopathic scrotal edema [1]. This study is aimed to find out the efficacy of Ultrasound (US) with color Doppler for diagnostic purpose of different acute scrotal condition. Here we included only the children patients with sudden onset of scrotal swelling with pain without $\mathrm{H} / \mathrm{O}$ of trauma or any other history of mass previously. However, there is, mimicking in the clinical presentation of the different causes of acute scrotal pain. Imaging in clinically similar l cases may lead to an early diagnosis of testicular torsion, and thus, decrease the number of unnecessary surgeries. If we can diagnose early by color Doppler, it may decrease morbidity a lot. For this we want to see the efficacy of US with color Doppler so that surgeon can take early decision as well as can avoid unnecessary surgery. A study results reported that US can prevent the need for scrotal exploration and can shortened hospital stays. The study was conducted between two groups comparing primary scrotal exploration and initial US examination with exploration [2].

\section{Methodology}

It was a 3 years long prospective observational study conducted at Radiology department of Dhaka Shisha Hospital from January,2013 to December,2016. All US was done by a single radiologist, twice a week, on her duty hours. In this time the children who have visited here with acute scrotal pain with swelling were included in the study. But who had H/O of trauma or previous Mass history were excluded from the study. These patients were subjected to high frequency ultrasonography and color Doppler using standard machine (Symens monoline G-40 \& Simons Accustom NX 3 Elite) equipped with high resolution and 


\section{Current Trends in Clinical \& Medical Imaging}

color Doppler linear probe. Serial transverse and sagittal images of each scrotum are obtained, and both testes are compared for echotexture and color flow. The study included both the scrotum and inguinal area. The clinical presentation, outcome, and US results were analyzed.

\section{Discussion and Results}

Acute scrotal pain is a medical emergency. Management protocol is totally different according to cause. Torsion of testis and strangulated hernia are surgical emergency; whereas, epididymis-orchitis is treated by medicines. Although, scrotal contents are the most accessible to clinical examination, serious confusion may occur. Due to severe pain, physical examination sometimes limited. In such condition non-invasive procedure like US with color Doppler play an important role to diagnosis. US with color Doppler is valuable in differentiating between medically treatable and surgical emergency of scrotum and avoiding unnecessary devastating surgical exploration [3]. Now, US with high frequency transducer in combination with color Doppler has become the imaging modality of choice for evaluation of acute scrotum in many countries.

Table 1: US diagnosis in Acute scrotum.

\begin{tabular}{|c|c|c|}
\hline Name of Condition & $\begin{array}{c}\text { Number } \\
\text { of Cases }\end{array}$ & $\begin{array}{c}\text { Number of } \\
\text { Diagnosed by US }\end{array}$ \\
\hline $\begin{array}{c}\text { Epididymo-orchitis, epididymitis, } \\
\text { funiculitis }\end{array}$ & 87 & 83 \\
\hline Torsion & 58 & 55 \\
\hline Obstructed/Strangulated hernia & 5 & 9 \\
\hline Others like hydrocele, varicocele & 3 & 6 \\
\hline
\end{tabular}

In the current study, we examined 153 patients presenting with acute scrotal pain by color Doppler ultrasonography. The results of these imaging studies were correlated with final diagnosis established by means of surgery or clinical followup (Table 1). In this study testicular torsion is most common in males of age group 8-15 years, but it can occur at any age. As it is an emergency condition to [reserve testis, early diagnosis is very important. This initially results in testicular venous outflow obstruction, subsequent engorgement, arterial obstruction, and rapid irreversible testicular infarction, normally within $6 \mathrm{~h}$ of onset. [4] There are two types of testicular torsion: Intravaginal and extravaginally. Intravaginal torsion is the more common type, occurring most frequently at puberty. It results from anomalous suspension of the testis by a long stalk of spermatic cord, resulting in complete investment of the testis and epididymis by the tunica vaginalis. This anomaly has been likened to a bell-clapper. Anomalous testicular suspension is bilateral in $50-80 \%$ of patients. Extravaginally torsion most often occurs in newborns without the "bell clapper" deformity. It is thought to result from a poor or absent attachment of the testis to the scrotal wall, allowing rotation of the testis, epididymis, and tunica vaginalis as a unit and causing torsion of the cord at the level of the external ring [5].
Usually, testicular torsion presents with sudden onset, severe scrotal pain with associated swelling, nausea, and vomiting. Atypical presentations are also not uncommon [6]. The physician needs to be aware that an embarrassed child may state that he has lower abdominal or inguinal pain rather than scrotal pain. A child may also minimize his symptoms out of fear. On examination, high lying, transverse testis may be seen. In addition, there may be loss of the cremasteric reflex; lifting the testis does not abolish the pain (Prawn's sign) $[4,6]$. This can be a difficult clinical sign to elicit and has shown significant clinician variance. This large inconsistency makes it unsuitable as an adequate screening or diagnostic test [7]. On gray scale sonography, in acute torsion, testis appears enlarged, but echogenicity remains normal if reported early within 1-6 hours. But with time it becomes heterogenous and hypoechoic compared with contralateral normal testis.
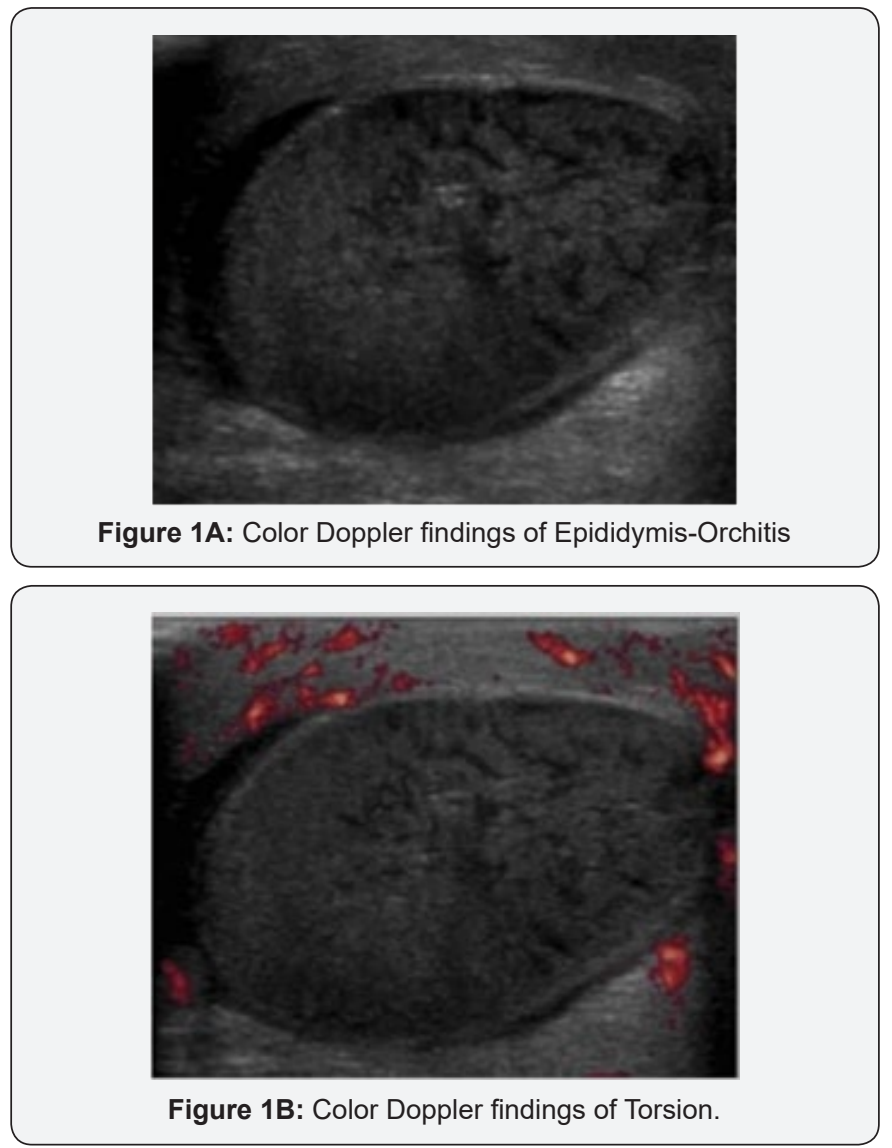

Table 2: US diagnosis in testicular Torsion.

\begin{tabular}{|c|c|}
\hline Torsion & \\
\hline True Positive & 55 \\
\hline True negative & 95 \\
\hline False Positive & 0 \\
\hline False negative & 3 \\
\hline
\end{tabular}

The gray-scale findings of acute and subacute torsion are not specific and may be seen in testicular infarction caused by epididymitis, epididymis-orchitis, and traumatic testicular 


\section{Current Trends in Clinical \& Medical Imaging}

rupture or infarction. [5] Color Doppler sonography (Figure 1a) shows absent blood flow in the affected testicle [8] or significantly less than in the normal, contralateral testicle as shown in Figure 1b. The spermatic cord immediately cranial to the testis and epididymis is twisted and intrastromal portion of the cord appears as edematous, round, ovoid or curled echogenic extra-testicular mass, with the epididymal head wrapped around it causing a characteristic torsion knot or "whirlpool pattern" on color doppler $[4,5,9]$. Torsion of at least $540^{\circ}$ is necessary for complete arterial occlusion. With partial torsion of $360^{\circ}$, or less, arterial flow may still occur, but venous outflow is often obstructed, causing diminished diastolic arterial flow on spectral Doppler examination [10]. If spontaneous detorsion occurs, flow within the affected testis may be normal, or it may be increased and mimic orchitis [5,11] (Tables $2 \& 3$ ).

Table 3: Accuracy of US in diagnosis of Torsion.

\begin{tabular}{|c|c|}
\hline Torsion & \\
\hline Positive predictive Value & $100 \%$ \\
\hline Negative predictive Value & $96.90 \%$ \\
\hline Specificity & $100 \%$ \\
\hline Sensitivity & $94.80 \%$ \\
\hline
\end{tabular}

In our study, out of 153 patients presenting with acute scrotal pain, 55 were diagnosed to be having torsion testis by color Doppler but surgical diagnosis revealed 58. Almost all cases were correctly diagnosed with color Doppler ultrasonography. There was no false positive diagnosis of testicular torsion. The study demonstrated $100 \%$ specificity and $94.8 \%$ sensitivity for testicular torsion. Positive and negative predictive value (PPV and NPV) for testicular torsion was found to be $100 \%$ and $96.9 \%$. The most common age group in our study were between 8 and 14 years of age. Depending on the duration of the process, the morphologic appearance of torsion on follow up by surgery and histopathology were intense congestion to widespread extravasation of blood into the interstitial tissue to hemorrhagic testicular infarction.

Table 4: US diagnosis in Epididymis-orchitis.

\begin{tabular}{|c|c|}
\hline Epididymo-orchitis & \\
\hline True Positive & 83 \\
\hline True negative & 66 \\
\hline False positive & 0 \\
\hline False negative & 4 \\
\hline
\end{tabular}

Table 5: Accuracy of US in diagnosis of epididymis-orchitis.

\begin{tabular}{|c|c|}
\hline Epididymo-orchitis & \\
\hline Positive predictive Value & $100 \%$ \\
\hline Negative predictive Value & $94.30 \%$ \\
\hline Specificity & $100 \%$ \\
\hline Sensitivity & $95.40 \%$ \\
\hline
\end{tabular}

Usually epididymis-orchitis is a disease condition of post pubertal age group [5] In our study group we found in 14-16 years age groups (Tables 4 \& 5). Typically, patients present with the deceptive onset of scrotal pain and swelling with associated fever, rigors, and lower urinary tract symptoms such as increased frequency, dysuria, and urgency $[5,6]$.

In acute epididymitis, sonography characteristically shows thickening and enlargement of the epididymis, involving the tail initially and frequently spreading to the entire epididymis. The echogenicity of the epididymis is usually decreased, and its echotexture is often coarse and heterogeneous. Testicular involvement usually diffuses and in $10 \%$ focal (adjacent to enlarged portion of epididymis) and they appear hypoechoic. Reactive hydrocele formation is common, and associated skin thickening may be seen. Color flow Doppler sonography usually shows increased blood flow in the epididymis or testis, or both, compared with the asymptomatic side. When vascular disruption is severe, resulting in complete testicular infarction, the changes are indistinguishable from those seen in testicular torsion. The important distinction is on spectral Doppler, in epididymitis there is high flow and low resistive index in comparison to high resistive flow found in torsion of the spermatic cord $[5,12]$. Diastolic flow reversal in the arterial waveforms of the testis is an ominous finding, associated with testicular infarction in severe epididymis-orchitis $[5,13]$

In our study, we diagnosed 83 cases as epididymis-orchitis by color Doppler ultrasonography who had findings with a straight spermatic cord, a swollen epididymis, testis, or both, an absent focal lesion in the testis, and increased flow on color Doppler studies along with the clinical features of infection. Out of 83 positive diagnosis made by US, four were found to be false positive on clinical follow-up, of which one being diagnosed as omental hernia and other being varicocele limited to inguinal region, which were misdiagnosed as funiculitis. An 18 years old boy came to us with pain. Gray scale B-mode US image showed a mildly hyperechoic oval, inhomogeneous mass in the region of the left spermatic cord. The mass was located just above the left epididymis and showed marked vascularity on power and color Doppler imaging. We misdiagnosed it as funiculitis. Hence, Valsalva maneuver should be done to differentiate funiculitis from varicocele [12] in case of doubt. On clinical follow-up of 153 patients, 87 patients are found to be having epididymis-orchitis/ funiculitis. The study demonstrated $100 \%$ specificity and $95.4 \%$ sensitivity for epididymis-orchitis. PPV and NPV for epididymisorchitis was found to be 100 and $94.3 \%$, respectively.

An acute inguinal hernia may also present as an acute scrotum. In this case, pain and swelling involve both the scrotal contents and the groin area. On US: The hernial sac most commonly contains bowel, while its next most common contents are momentum. Gray-scale US findings include a fluidor air-filled loop of bowel in the scrotum. The presence of realtime peristalsis is diagnostic for the presence of bowel If the momentum has herniated, hyperechoic areas are present and correspond to omental fat. Bowel strangulation is more common in indirect than in direct inguinal hernia. An akinetic dilated loop of bowel observed at US in the hernial sac is reported to 


\section{Current Trends in Clinical \& Medical Imaging}

have high sensitivity and specificity for the recognition of bowel strangulation $[12,14]$. Hyperemia of scrotal soft tissue and bowel wall are suggestive of strangulation.

In our study, we found nine case of obstructive inguinoscrotal hernia diagnosed by US, which was later confirmed by follow-up.

\section{Conclusion}

In this study we have found that US with color Doppler is a very efficient tool to diagnosis acute sortal management and may guide the surgeon to take management decision and we can avoid unnecessary surgical hazards to the patients.

\section{References}

1. Remer EM, Casalino DD, Arellano RS, Bishoff JT, Coursey CA, et al. (2012) ACR Appropriateness Criteria acute onset of scrotal painwithout trauma, without antecedent mass. Ultrasound Q 28(1): 47-51.

2. Lam WW, Yap TL, Jacobsen AS, Teo HJ (2005) Color Doppler ultrasonography replacing surgical exploration for acute scrotum: Myth or reality? Pediatr Radiol 35(6): 597-600.

3. Khaleghnejad Tabari A, Mirshermirani A, Rouzrokh M, Mahmudi M Baghaiepour MR, et al. (2010) Early Exploration in the management of acute scrotum in children. Iran J Pediatr 20(4) :466-470.ssss

4. Yusuf GT, Sidhu PS (2013) A review of ultrasound imaging in scrotal emergencies. J Ultrasound 16(4): 171-178.
5. Gorman B (2011) The Scrotum. In: Rumack CM (Eds.), Diagnostic Ultrasound. ( $4^{\text {th }}$ edn), Elsevier, USA, 1: 864-869.

6. Srinath H (2013) Acute scrotal pain. Aust Fam Phys 42(11): 790-792.

7. Davis JE, Silverman M (2011) Scrotal emergencies. Emerg Med Clin North Am 29(4): 469-484.

8. Liang T, Metcalfe P, Sevcik W, Noga M (2013) Retrospective review of diagnosis and treatment in children presenting to the pediatric department with acute scrotum. AJR Am J Roentgenol 200(5): W444-9.

9. Vijayaraghavan SB (2006) Sonographic differential diagnosis of acute scrotum: Real-time whirlpool sign, a key sign of torsion. J Ultrasound Med 25(5): 563-574.

10. Cassar S, Bhatt S, Paltiel HJ, Dogra VS (2008) Role of spectral Doppler sonography in the evaluation of partial testicular torsion. J Ultrasound Med 27(11): 1629-1638.

11. D Andrea A, Coppolino F, Cesarano E, Russo A, Cappabianca S, et al. (2013) US in the assessment of acute scrotum. Crit Ultrasound J 15(1): S8.

12. Pepe P, Panella P, Pennisi M, Aragona F (2006) Does color Doppler sonography improve the clinical assessment of patients with acute scrotum? Eur J Radiol 60(1): 120-124.

13. Prando D (2009) Torsion of the spermatic cord: The main grayscale and doppler sonographic signs. Abdom Imaging 34(5): 648-661.

14. Wright S, Hoffmann B (2014) Emergency ultrasound of acute scrotal pain.

Your next submission with Juniper Publishers will reach you the below assets

- Quality Editorial service

- Swift Peer Review

- Reprints availability

- E-prints Service

- Manuscript Podcast for convenient understanding

- Global attainment for your research

- Manuscript accessibility in different formats

( Pdf, E-pub, Full Text, Audio)

- Unceasing customer service

Track the below URL for one-step submission https://juniperpublishers.com/online-submission.php 